\title{
Heat-related cardiovascular mortality risk in Cyprus: a case-crossover study using a distributed lag non-linear model
}

\author{
Małgorzata J Lubczyńska", Costas A Christophi ${ }^{2,3}$ and Jos Lelieveld ${ }^{1,4}$
}

\begin{abstract}
Background: The frequency and intensity of heat waves is projected to increase in many parts of the world, particularly in regions such as the Eastern Mediterranean and Middle East (EMME), where the warming trends are much larger than the global average. The relationship between air temperature and premature mortality is widely recognized, however, it is not well defined in the aforementioned region.

The objective of this study is to assess the relationship between cardiovascular mortality risk and air temperature in Cyprus, an island located centrally in the EMME.

Methods: Daily cardiovascular mortality data and spatially aggregated daily mean, maximum, and minimum temperatures for the period 2004-2010 were analyzed using a case-crossover design combined with a distributed lag non-linear model.

Results: A relationship between high temperatures and cardiovascular mortality was observed for cerebrovascular diseases, ischaemic and other heart diseases; this relationship was exacerbated on days with high temperatures. The highest relative risk was observed on the day of the heat event and remained significantly elevated for another day. The results were consistent regardless whether the minimum, maximum, or mean temperatures were used, although the association seems to be more pronounced with the mean temperatures, which suggests that consecutive high day- and night-time temperatures are the most hazardous.

Conclusions: The identification of a positive relationship between high temperatures and cardiovascular mortality in Cyprus raises concerns. In view of the projected climate changes and strong increases in extreme heat events in the region, appropriate interventions need to be developed.
\end{abstract}

Keywords: Temperature, Cardiovascular mortality, Climate change, Cyprus, Distributed lags, Case-crossover

\section{Background}

The relationship between air temperature and premature mortality is widely recognized. Many studies, in various geographical locations, have reported that both spells of extremely low and extremely high temperatures can cause excess mortality [1-4]. However, differences in heat sensitivity, coping capacity, and adaptation measures of different populations, as well as climatic differences across the globe, can influence the relationship of air temperature with mortality and cause it to be region specific [3]. This

\footnotetext{
* Correspondence: mjlubczynska@gmail.com

${ }^{1}$ Energy, Environment and Water Research Center, The Cyprus Institute, Nicosia, Cyprus

Full list of author information is available at the end of the article
}

implies that the relationship between air temperature and mortality, as reported for a certain region, cannot be directly extrapolated to other regions with, for example, different climatic zones, without introducing errors.

Following scientific consensus on the projected global warming, an overall substantial increase in air temperature, at least partially induced by humans, has been observed, while heat waves are very likely to increase in frequency and intensity in the future [5]. A recent study showed that the Eastern Mediterranean and Middle East (EMME) region is a climate change hotspot where temperatures increase more rapidly than elsewhere. For example, within the $20^{\text {th }}$ century, in many locations throughout the EMME region, warming trends of $0.4^{\circ} \mathrm{C}$ per decade were observed, 
a tendency that is much larger than the global average [6]. It is projected that this will continue in future and will be combined with a significant reduction of rainfall giving rise to a dramatic increase in hot weather extremes in most parts of the region [7].

These projections make it of paramount importance to develop a solid understanding of the relationship between temperature and mortality in the EMME region, despite alleviation in the increase in heat-related mortality observed over the course of the last century in various parts of the world [8-11]. This alleviation is mainly attributed to the implementation of adaptation measures, such as the wide use of residential air-conditioning systems. This is true in Cyprus as well where about $80 \%$ of households are equipped with one or more air-conditioning units [12]. However, despite of these measures, the mortality rate that is attributed to extreme heat events appears to be elevated.

In general, the incidence of heat-related mortality is the highest among the elderly and people with compromised health, according to studies originating mainly from the US, Europe, and Australia [13,14]. Cardiovascular diseases are among the main underlying causes of death during heat waves, defined as prolonged periods of unusually high air temperatures [2,13-17]. The present study focuses on heat-related cardiovascular mortality in the southern part of Cyprus, the area that is under the control of the Republic of Cyprus (hereafter referred to as Cyprus). The northern part of the island, where Republic of Cyprus has no effective control, is not included in this study.

The relation between high air temperatures and mortality in the EMME region has been a focus of interest in a limited number of studies. A significant association between temperature and total daily mortality has been established for the area of Greater Beirut [18]. This relationship has also been found to exist in Athens, Greece, where both cold and hot conditions were significant risk factors for daily natural cause mortality [19]. In an international study of temperature, heat and urban mortality clear evidence was found of increasing death rates from all non-external causes with increasing heat in the northern part of the EMME domain [20]. Another European study concluded that, in terms of health impact, the changing geographical patterns of high-impact heat waves will be most severe in the Mediterranean region which partly overlaps with the EMME region [16]. However, to our knowledge no study has focused specifically on heatrelated cardiovascular mortality in the EMME region.

The objective of this research is to assess heat-related cardiovascular mortality in the EMME region using data from Cyprus, which geographically can be considered as the center of the region. Such direct approach is more appropriate than the use of existing models based on data from other parts of the world, such as the United States or Northern Europe, where heat sensitivity, coping capacity, adaptation measures, and climate conditions are different.

The present study is based on recent data, 2004-2010 time-series of air temperatures, and explicit categories of cardiovascular mortality in Cyprus.

\section{Methods}

\section{Data collection}

Cyprus is an island centrally located in the EMME region at about $35^{\circ}$ north latitude and $33^{\circ}$ east longitude. The geomorphology of Cyprus is marked by two mountainous areas; the Kyrenia range in the northern part of the island and the Troodos range largely in the southern part, with the highest elevation reaching $1952 \mathrm{~m}$ above sea level.

There are five main urban areas in the southern part of Cyprus, which account for approximately $67 \%$ of the total population of 840,400 inhabitants in 2011 [21]. The age-distribution of the population in the study area is not exactly proportional to the total population, with more children, adolescents and elderly living in the rural environment and people between 20 and 55 years old living in urban areas. However, these differences are not very profound (Figure 1).

\section{Mortality data}

The selection of the disease categories for inclusion in this study, with Cyprus as the study area, was based on the availability of data for the entire EMME region in the World Health Organization mortality database in order to maintain consistency with follow-up studies. The diseases for which records were available for each country within the EMME region were evaluated for their relevance with respect to temperature, based on expert opinion and a search of the literature. The final selection consisted of five categories of cardiovascular diseases, classified according to the $10^{\text {th }}$ revision of the International Classification of Diseases (ICD10): hypertensive diseases (I10-I13); ischaemic heart diseases (I20-I25); other heart diseases (I26-I51); cerebrovascular diseases (I60-I69); and remainder of diseases of the circulatory system (I71-199) [22]. Daily mortality data on these five categories were then provided by the Ministry of Health in Cyprus for the period between 2004 and 2011 [23]. As the daily temperature time series available include data only until $31 / 12 / 2010$, the study period in this research is limited to the period from $1 / 1 / 2004$ until 31/12/2010.

Over this 7-year period, the total mortality related to the five categories of cardiovascular diseases considered in this study equaled 13,889 cases. The contribution per category to the total number of deaths is as follows: I10-I13 - 1220 cases (8.8\%); I20-I25 - 4773 cases 


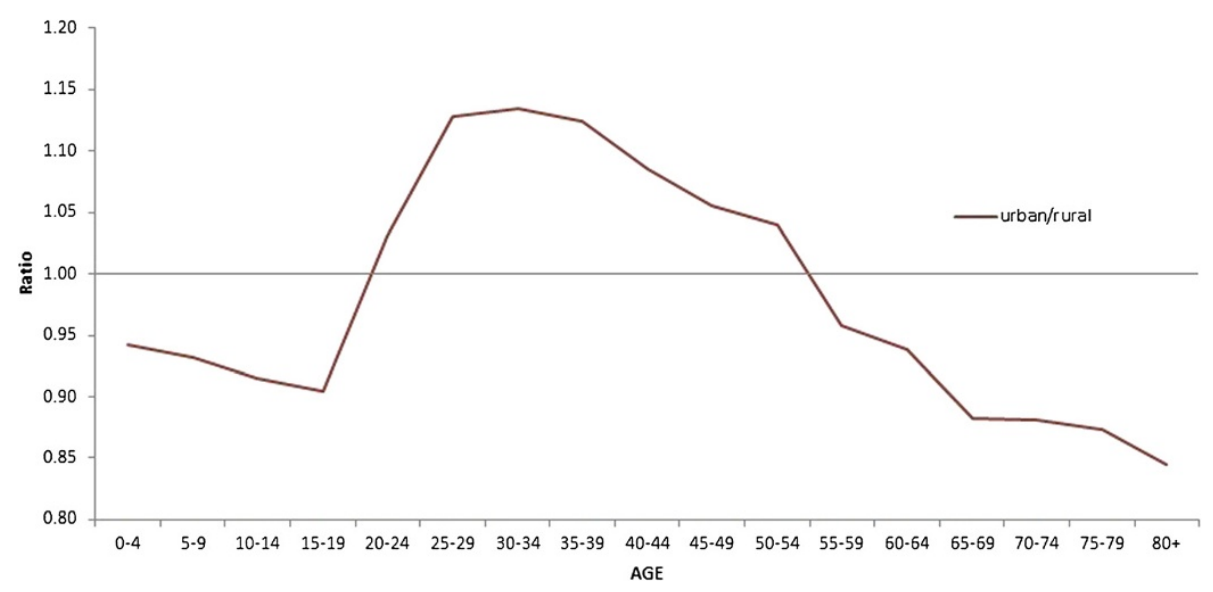

Figure 1 Urban-to-rural population ratio in Cyprus per age category, 2011 [21].

(34.4\%); I26-I51 - 4595 cases (30.1\%); I60-I69 - 2893 cases (20.8\%); and I71-I99 - 408 cases $(2.9 \%)$. No other relevant information aside from the date of death and the primary cause of death was provided in the database.

These diseases include anomalies in the blood flow. It is hypothesized that heat can further exacerbate these anomalies through vasodilation and/or dehydration, which could lead to hypovolemia [24,25]. Since blood transports oxygen to the organs, decreased blood flow could lead to insufficient oxygen supply throughout the human body which could cause organ damage, resulting, in the worst case, in premature death.

\section{Meteorological data}

The climate of Cyprus is predominantly subtropical, with daily mean summer temperatures ranging from $22^{\circ} \mathrm{C}$ in the high altitude areas to $29^{\circ} \mathrm{C}$ in the low altitude areas and daily maximum summer temperatures varying between $27^{\circ} \mathrm{C}$ and $36^{\circ} \mathrm{C}$, respectively. The daily mean winter temperatures vary between $3^{\circ} \mathrm{C}$ and $10^{\circ} \mathrm{C}$ and the daily minimum winter temperatures between $0^{\circ} \mathrm{C}$ and $5^{\circ} \mathrm{C}$ in the high and low altitude areas, respectively [26].

The meteorological data used in this study originated from the Department of Meteorology of the Ministry of Agriculture in Cyprus. Daily minimum $\left(\mathrm{T}_{\mathrm{min}}\right)$, maximum $\left(\mathrm{T}_{\max }\right)$ and mean $\left(\mathrm{T}_{\text {mean }}\right)$ temperatures were used in our analysis where $\mathrm{T}_{\min }$ and $\mathrm{T}_{\max }$ are daily (24-hour) observed extremes between 8:00am and 7:59am. Therefore $\mathrm{T}_{\text {min }}$, which generally occurs early in the morning, has a 1-day calendar day delay. Since $\mathrm{T}_{\text {mean }}$ combines the highest and the lowest measured temperatures within the 24-hour window, it can be seen as a representative value for consecutive day- and night-time temperature.

The measurements were taken at 34 weather stations distributed across Cyprus and located at various altitudes (Figure 2). As the available mortality time series database lacks spatial association and is characterized merely by one daily mortality value per disease for the entire study area, the daily temperature records were spatially averaged in order to create one representative daily value for the whole area. In order not to lose the spatial association of the temperature measurements, spatial averaging was based on weighing according to the population density, assuming that mortality is proportional to the population size: (Additional file 1). The population data were obtained from the Statistical Service of Cyprus [21].

The extent to which humidity plays a role in the temperature-mortality relationship is not entirely clear. Some studies suggest that humidity is an important component in the above mentioned relationship as it plays an essential role in the human thermoregulation, while other studies report a lack of such dependence [2]. Since the role of humidity in the temperature-mortality relationship is not well recognized and also because of the poor quality of the humidity database available, this study focused only on the association of temperature with cardiovascular mortality.

\section{Data analysis}

The analysis of the relationship between temperature and cardiovascular mortality was carried out by applying a distributed lag non-linear model (DLNM) to a casecrossover design. A DLNM estimates the non-linear and the delayed effects of temperature on mortality using cross-basis functions to describe this relationship along the dimensions of temperature and lag simultaneously. These functions can be chosen independently for the two dimensions permitting a flexible fit $[27,28]$.

The case-crossover design is a special case of a timeseries analysis, wherein long-term and seasonal trends are controlled for by design through the use of relatively short time windows, namely, one calendar month in this study [27]. 


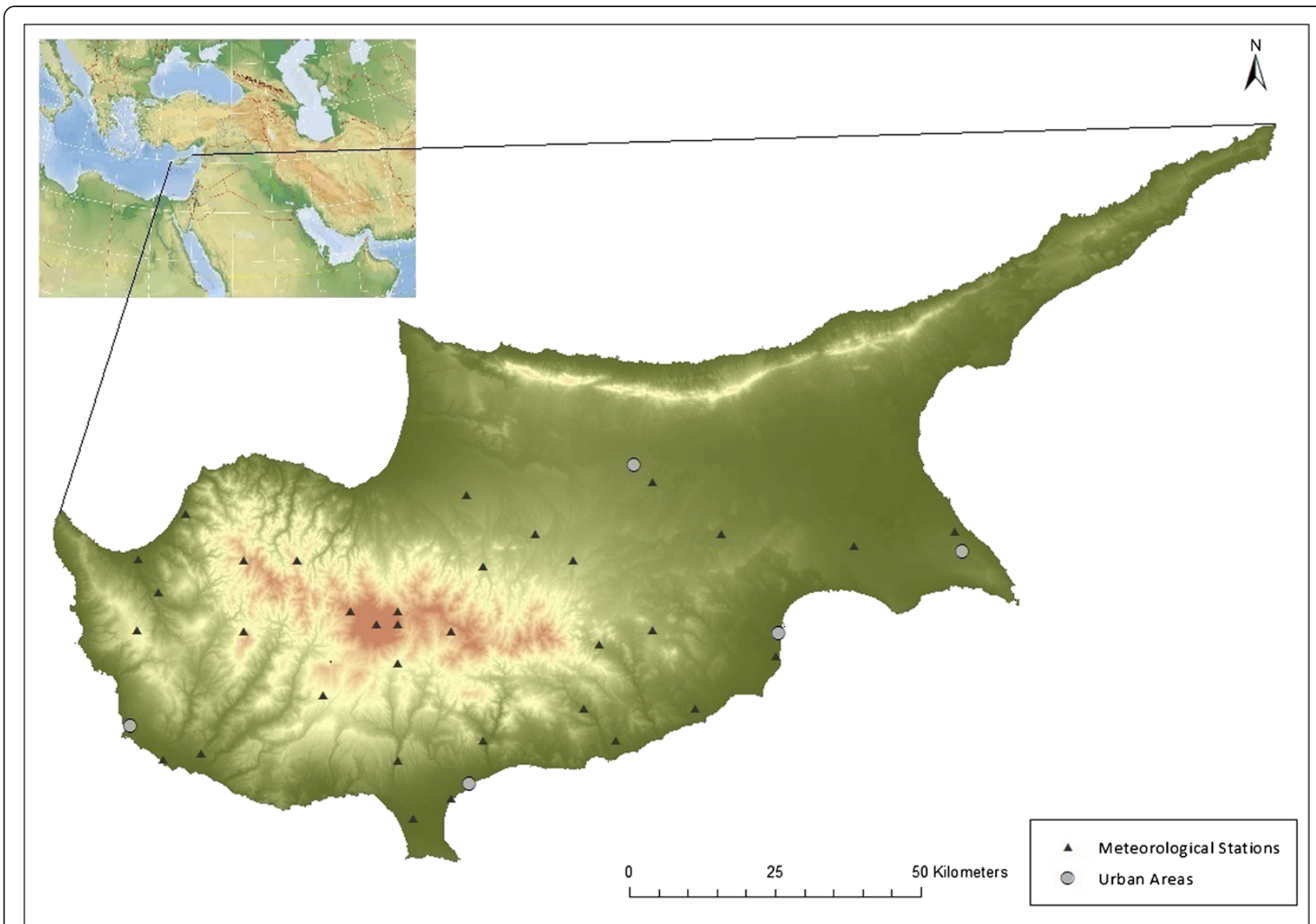

Figure 2 Distribution of meteorological stations and the main urban areas.

Applying a DLNM to a case-crossover design permits a flexible assessment of the non-linear and delayed effects of temperature on mortality and corrects for the effects of seasonality by design [27]. In order to combine the DLNM with the case-crossover design, a Poisson regression model was used, which allows for overdispersion:

$$
\begin{aligned}
& Y_{t} \sim \text { Poisson }\left(\mu_{t}\right) \\
& \log \left(\mu_{t}\right)=\alpha+\beta T_{t, l}+\lambda \text { Strata }_{t}+\eta D O W_{t}
\end{aligned}
$$

where $t$ is the day of the observation; $Y_{t}$ is the mortality count on day $t$; $\alpha$ is the intercept; $T_{t, l}$ is the matrix that is obtained when the DLNM is applied to temperature; $\beta$ is a vector of coefficients for that matrix; and $l$ is the lag in days. Strata ${ }_{t}$ represents the case-control strata, a variable for the year and month that is used to control for long-term and seasonal trends; $\lambda$ is a vector of coefficients and $D O W_{t}$ is the day of the week on day $t$, with $\eta$ being a vector of coefficients [27].

As the cross-basis functions to describe the temperature-response relationship can be independently chosen for temperature and lag, a quadratic basis spline was used for temperature and a natural cubic spline was used for the lag. In the quadratic basis spline, 4 degrees of freedom were used, and the knots were by default located at evenly distributed percentiles. For the natural cubic spline 4 degrees of freedom were selected and the boundary knots were by default placed at the range of the predictor, here lag 0 and lag 10. The choices of the degrees of freedom were based on the literature $[27,29]$ and optimized with modified Akaike and Bayesian information criteria (QAIC and QBIC) [28]:

$$
\begin{aligned}
& Q A I C=-2 L(\hat{\theta})+2 \hat{\varnothing} k \text { and } \\
& Q B I C=-2 L(\hat{\theta})+\log (n) \hat{\varnothing} k
\end{aligned}
$$

where $L$ is the log-likelihood of the fitted model; $\hat{\theta}$ represent the parameters of the fitted model; ${ }^{\wedge}$ is the estimated overdispersion parameter; $k$ represents the total number of parameters; and $n$ is the total number of observations.

The model that minimizes these two criteria was selected as the final model. For the purpose of this study, 
the "dlnm" package of $\mathrm{R}$ software was used $[28,30]$. The DLNM uses one value of temperature as the reference for the estimates that are expressed in terms of relative risk. The median temperatures for each of the three daily temperature series used in this study, i.e. $\mathrm{T}_{\max }$, $\mathrm{T}_{\text {mean }}$ and $\mathrm{T}_{\text {min, }}$, were selected as these reference values and they equaled $25.9^{\circ} \mathrm{C}, 20.0^{\circ} \mathrm{C}$, and $14.1^{\circ} \mathrm{C}$, respectively (Table 1).

Three-dimensional diagrams were produced that present the relationships between temperature and the different categories of cardiovascular mortality at the total range of lags, in terms of relative risk, as compared to the risk at the reference temperature. Plots showing the effect of a specific temperature and lag values on aggregated cardiovascular mortality are also presented. Since the focus of this study is on the right tail of the temperature distribution, the selected temperatures are all above the reference value and represent the $90^{\text {th }}$, $95^{\text {th }}$, and $99^{\text {th }}$ percentiles of the distribution. Furthermore, the maximum value of each temperature series is added to the selection (Table 1). In the analysis, the maximum temperature was rounded down to the largest integer value within each temperature range. Rounding down instead of up was used to prevent the integer from falling outside the recorded temperature range. The temperatures corresponding to the $90^{\text {th }}, 95^{\text {th }}$, and $99^{\text {th }}$ percentiles of the time series fall within the recorded temperature range and were therefore rounded up.

In the sensitivity analysis, the maximum lag was changed to 5,15 , and 20 days. In addition, the window length of the calendar month in the case-crossover design was changed to 30,28 , and 21 days. The results were analyzed by comparing the estimated relative risks at $90^{\text {th }}$, $95^{\text {th }}$, and $99^{\text {th }}$ percentiles of the temperature distribution. The estimated relative risks are presented along with the corresponding 95\% CI.

\section{Results}

Figures 3a-c present the relationship between different temperature time series and aggregated cardiovascular mortality (i.e., aggregated over all five selected categories of diseases) for different lags. The graphs indicate a substantial increase in relative mortality risk (RR) for the

Table 1 Values corresponding to reference temperature, the $90^{\text {th }}, 95^{\text {th }}$ and $99^{\text {th }}$ percentiles and to the upper limit of each temperature distribution are presented

\begin{tabular}{llll}
\hline & $\mathbf{T}_{\text {mean }}\left[{ }^{\circ} \mathbf{C}\right]$ & $\mathbf{T}_{\max }\left[{ }^{\circ} \mathbf{C}\right]$ & $\mathbf{T}_{\min }\left[{ }^{\circ} \mathbf{C}\right]$ \\
\hline Reference values & 20.0 & 25.9 & 14.1 \\
$90^{\text {th }}$ percentile & 28.4 & 34.6 & 22.2 \\
$95^{\text {th }}$ percentile & 29.4 & 35.6 & 23.3 \\
$99^{\text {th }}$ percentile & 31.2 & 37.4 & 25.3 \\
Upper limit & 33.6 & 39.9 & 27.9 \\
\hline
\end{tabular}

highest temperatures between lag 0 and lag 2 with the largest increase occurring on the actual day of the event (lag 0). An interesting observation is that the relative mortality risk on the actual day of the event was larger when using the daily mean temperatures (Figure 3a) than when using the daily maximum temperatures (Figure $3 \mathrm{~b}$ ). The analysis with daily minimum temperatures (Figure 3c) showed the lowest increases in relative risk as compared to the other two temperature time series.

Figures 4a-e present the association of mean temperature and cardiovascular mortality attributed to the different diseases. Very similar patterns were identified in the analyses with $\mathrm{T}_{\max }$ and $\mathrm{T}_{\min }$. Only the results obtained with $\mathrm{T}_{\text {mean }}$ are shown here as these presented the largest increases in relative risk. The relationships of $\mathrm{T}_{\text {mean }}$ with cerebrovascular diseases (Figure 4a), ischaemic heart diseases (Figure 4b) and other heart diseases (Figure 4c) show similar patterns as the aggregate ones (Figure 3a) with the increase in relative risk on the actual day of the event being the largest for ischaemic heart diseases, followed by cerebrovascular diseases, and then other heart diseases. On the other hand, hypertensive diseases (Figure 4d) and the remainder of the diseases of the circulatory system (Figure 4e) show a rather random behavior.

Figures $5 \mathrm{a}-\mathrm{c}$ illustrate the lag-specific associations for aggregated cardiovascular diseases for the three temperature time series, $\mathrm{T}_{\text {mean }}, \mathrm{T}_{\max }$, and $\mathrm{T}_{\text {min }}$, respectively. The pattern exhibited throughout the different ranges is very similar in all three cases, with $\mathrm{T}_{\text {mean }}$ showing slightly higher increases in relative mortality risk than $\mathrm{T}_{\max }$ and $\mathrm{T}_{\text {min }}$. Furthermore, a drop in relative risk around lag 3 and 4 in all three temperature analyses is observed, indicating a possible mortality displacement, also known as a harvesting effect [31]. Around lag 5, the relative risk is elevated again and remains above 1 until approximately lag 9 .

In order to analyze the effect of a specific temperature and lag values on aggregated cardiovascular mortality more closely, the associations along the temperature ranges at lags $0,1,2$, and 4 are plotted (Figure 6, left column); the associations along the range of lags ( 0 to 10) for the temperatures corresponding to the maximum value of the temperature range and the $99^{\text {th }}, 95^{\text {th }}$, and $90^{\text {th }}$ percentiles are also presented (Figure 6, right column). The grey shadings represent the $95 \% \mathrm{CI}$. Only the results for $\mathrm{T}_{\text {mean }}$ are presented because of the higher relative risks associated with $T_{\text {mean }}$ and the large similarity with the results obtained with both $\mathrm{T}_{\max }$ and $\mathrm{T}_{\min }$. The strong and significant increase in relative risk at lags 0 and 1 can be clearly seen in the figures, with the largest increase associated with the highest temperatures. Lags 2 and 4 show no significant effects. These results 

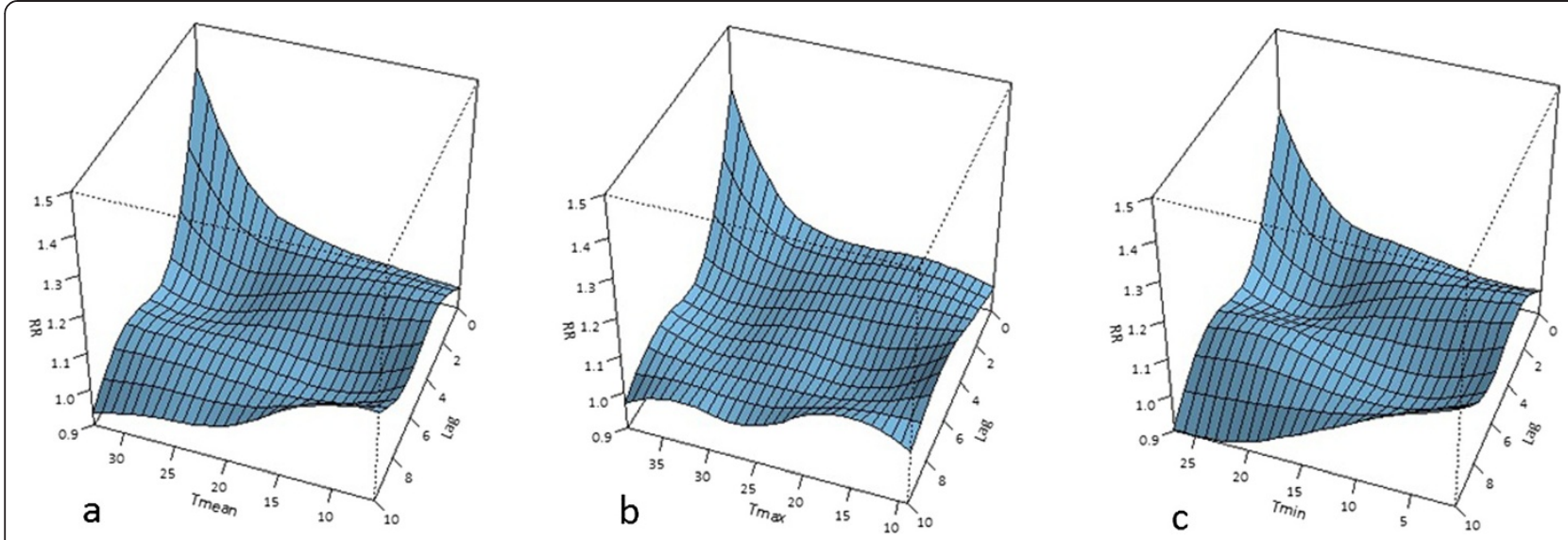

Figure 3 Relationship between temperature and relative mortality risks (RR) of aggregated cardiovascular diseases for lags ranging from 0 to 10 days for: (a) $T_{\text {meani }}$ (b) $T_{\text {max }}$ and (c) $T_{\text {min. }}$.

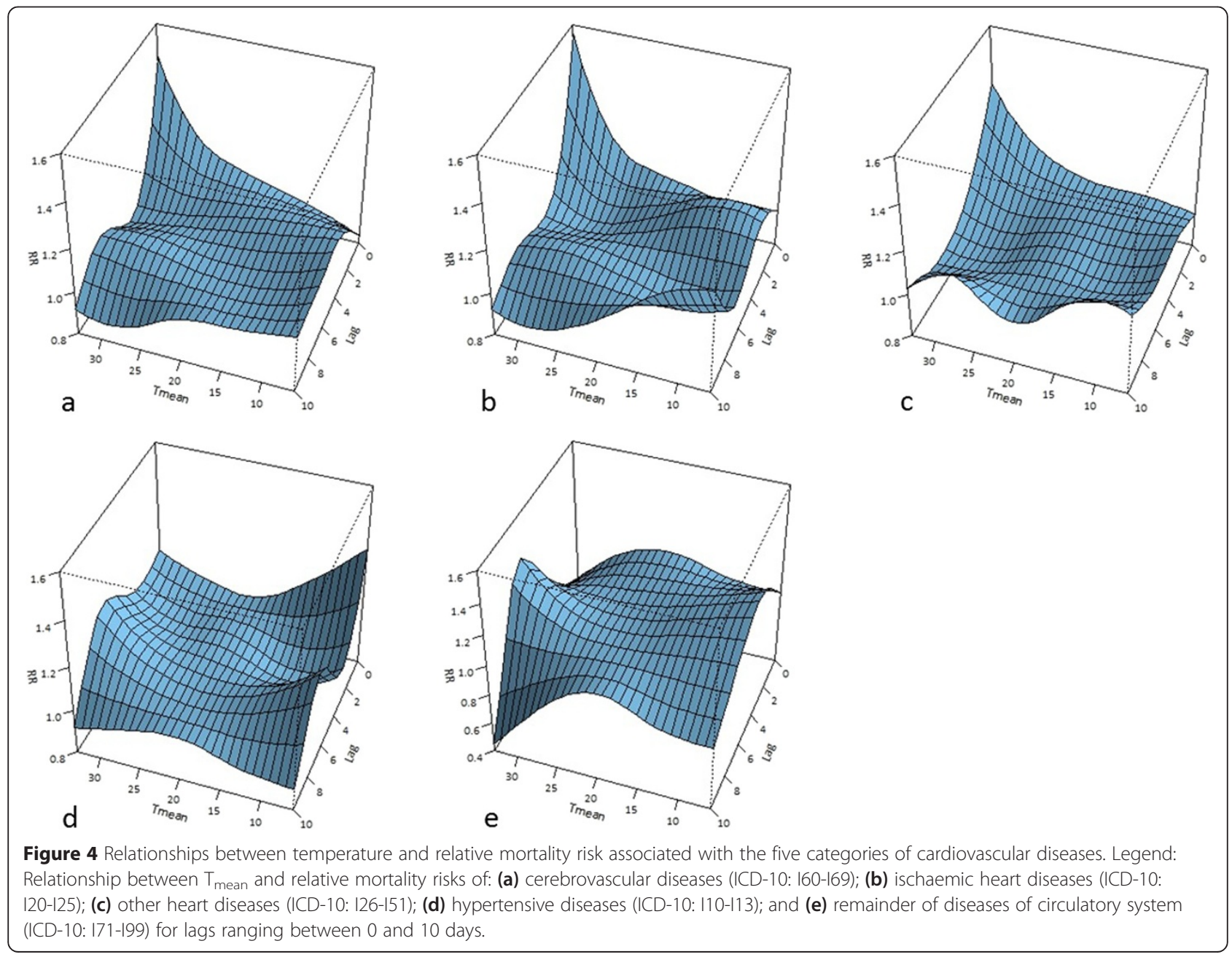



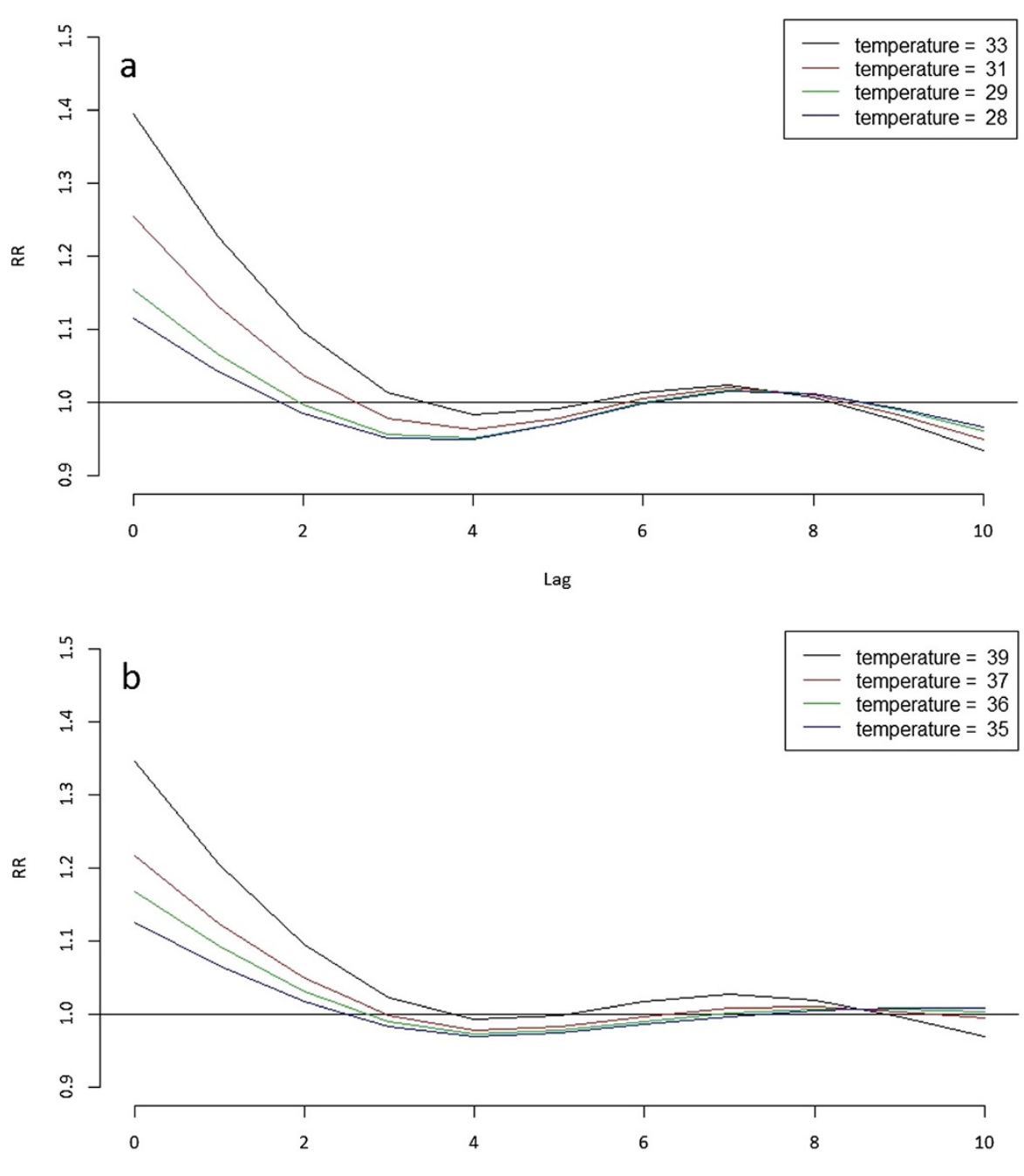

Lag

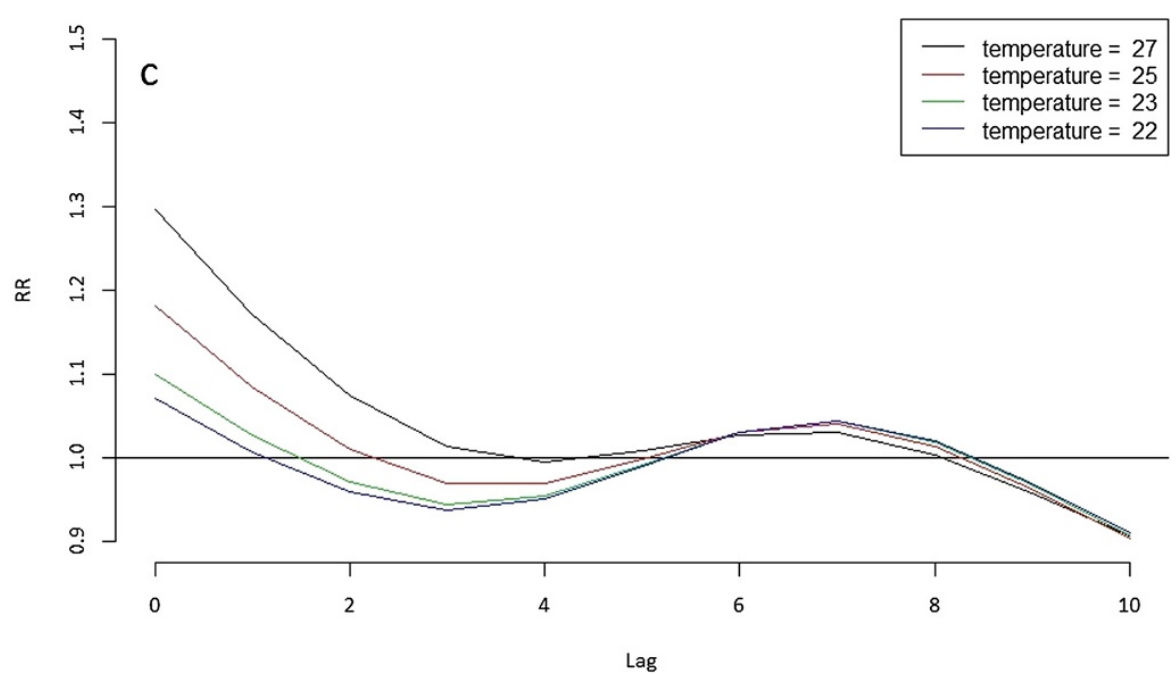

Figure 5 Lag-specific relative mortality risk associations for aggregated cardiovascular diseases. Legend: Lag-specific relative mortality risk (RR) associations for aggregated cardiovascular diseases at the temperatures corresponding to the $90^{\text {th }}$ (black), $95^{\text {th }}$ (red) and $99^{\text {th }}$ (green) percentiles of the temperature distribution and the maximum value (blue) of the temperature range for: (a) $T_{\text {meani }}$ (b) $T_{\text {maxi }}$ and (c) $T_{\text {min }}$. 


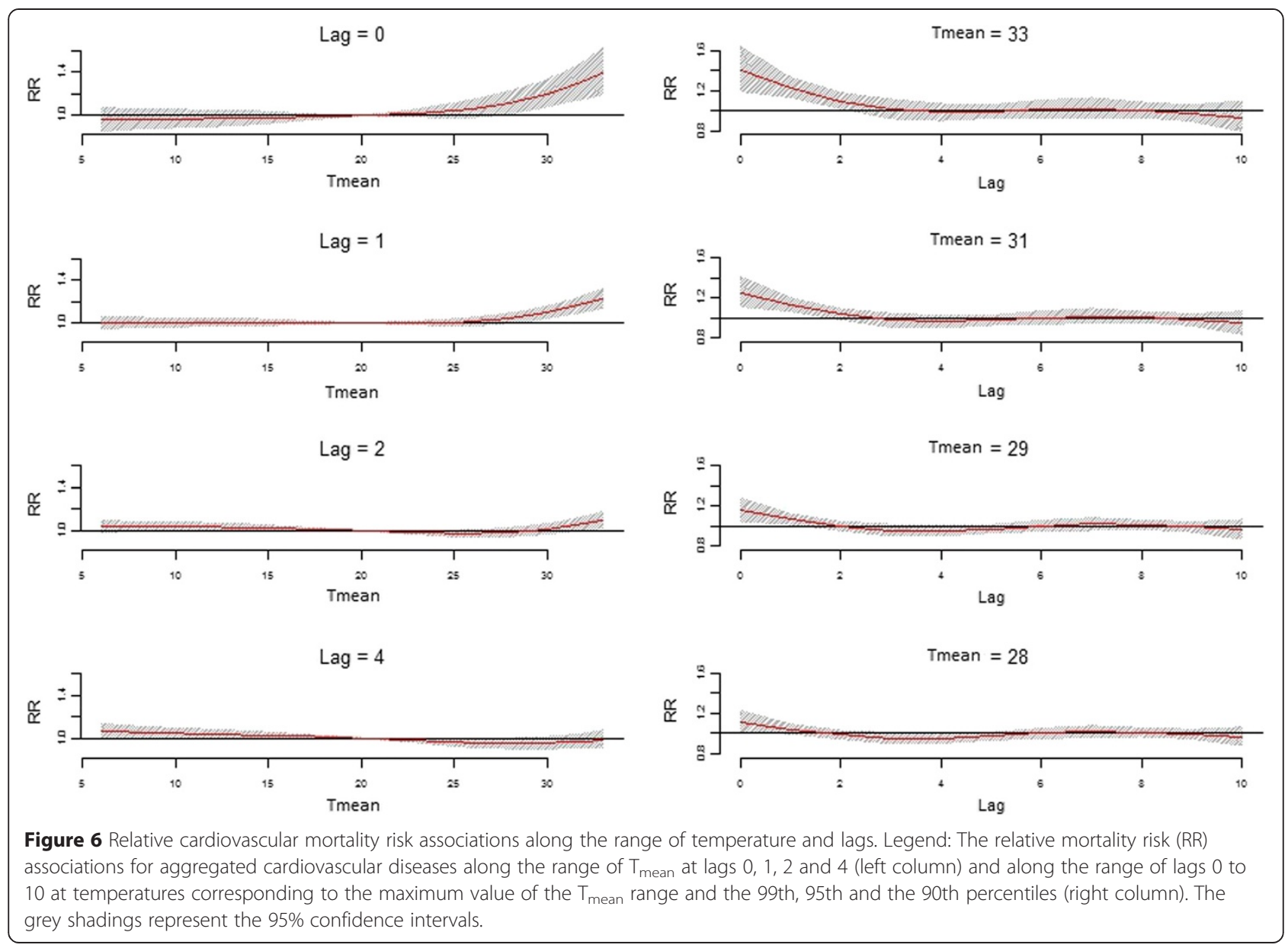

are consistent with $\mathrm{T}_{\max }$ and $\mathrm{T}_{\min }$ results (data not shown).

In addition to the case-crossover design, the DLNM was applied to a time-series design using a natural cubic spline with $7 \mathrm{df} /$ year to model the seasonal and long-time trends, including a factor for the day of the week. The results of that analysis were very similar to the results shown before, with overall slightly higher relative risks (data not shown). We focused on the case-crossover design since it removes any confounding by fixed characteristics as every case serves as its own control. Moreover, the case-crossover design controls for long-term and seasonal trends through a relatively short time windows, here a calendar month [27].

In order to find the model with the best fit, the number of the degrees of freedom was changed from 4 to 6 for both; temperature and lag. The combination that minimizes the Akaike and Bayesian information criteria, here the combination of $4 \mathrm{df}$ for temperature and $4 \mathrm{df}$ for lag, was selected as the final set-up (Additional file 2: Table S1).

\section{Sensitivity analysis}

Changing the maximum lag to 5, 15, and 20 days gave similar results when compared to the results obtained with the maximum lag set to 10 days (Additional file 3: Table S2). Furthermore, changing the window length of the calendar month in the case-crossover design to 30, 28 , and 21 days lead to similar results as compared to the original set-up (Additional file 4: Table S3). Therefore, we are convinced that the model used in this study is capable of capturing the main effects of high temperatures on cardiovascular mortality sufficiently.

\section{Discussion}

Despite the fact that no major differences were observed between the results using different temperature time series, the relative risk was highest for $\mathrm{T}_{\text {mean }}$ (Figures 3a and 5a). This suggests that the combination of high daytime temperatures with high temperatures at night is most harmful in the relationship between temperature and cardiovascular mortality. This is in line with findings of previous studies that argued that the thermoregulatory system of the human body can cope with extremely 
high temperatures as long as it has a sufficiently long period to cool down to normal temperatures following the hot period [15,32,33]. Consecutive high day and night time temperatures though prevent the human body from recovering from the heat stress.

In this study, the lowest increase in relative risk was associated with $\mathrm{T}_{\min }$. However, the extensive presence of household air-conditioning in Cyprus [12] might mask the actual effects of high night time temperatures on mortality risk, especially considering that the majority of the population stays indoors during the night hours. No information on the actual usage of air-conditioning in Cyprus was available, and since the prevalence does not necessarily reflect the actual use, the above statement cannot be regarded as conclusive.

The relationship of $\mathrm{T}_{\text {mean }}$ with cerebrovascular diseases (Figure 4a), ischaemic heart diseases (Figure 4b), and other heart diseases (Figure 4c) show very similar patterns compared to the results wherein all diseases in aggregate are included (Figure 3a). Given the prevalence of these diseases, as reported earlier, this is expected, as the three categories combined equal almost $90 \%$ of the total deaths included in this study.

On the contrary, hypertensive diseases (Figure 4d) and the remainder of the diseases of the circulatory system (Figure 4e) show a rather random and not significant behavior. This is likely due to the limited amount of data for these two groups and/or due to the possibility that these two disease categories are less influenced by temperature compared to the other three categories of diseases.

The relative risk on the actual day of the event is highest for ischaemic heart diseases, followed by cerebrovascular diseases and other heart diseases. These results imply that among the categories of the diseases studied here, people with ischaemic disorders are the most vulnerable to extremely high temperatures.

The lag specific associations at different temperatures show similar results for all three temperature time series (Figure 5a-c) with the highest relative risks at lag 0, lasting up to lag 2. In addition, the three plots imply decreasing relative risks around lag 3 and 4, indicating a possible harvesting effect. However, upon closer inspection (Figure 4), this protective effect around lag 3 and 4 does not seem to be significant. The lack of significance of the results beyond lag 2 is evident in the analyses with all three temperature time series. This also holds true for the elevated relative risk between lag 5 and lag 9 .

A limitation of the study is the lack of additional information about the cases, in particular their age, not allowing the use of a direct standardization method to account for the changing age-structure of the population, giving rise to potential bias due to the higher vulnerability of ageing populations to heat stress [2].
Moreover, due to the lack of information about the age of the cases, the spatial averaging of the temperature was based on weighing according to the population density without taking the age-structure into account. Since the age-structure is not exactly proportional to the overall population, this might lead to inaccuracy wherein urban meteorological records are given more weight, and therefore more influence in the final temperature time series due to denser population in the urban areas, while the vulnerability to heat-related cardiovascular mortality of that population is lower than the vulnerability of rural populations considering that people aged 20 to 55 years are over-represented in urban areas compared to rural areas. However, as it can be seen in Figure 1, these differences in age-structure between urban and rural areas in Cyprus are not very profound. Moreover, the temperature measurements are derived from 34 weather stations distributed fairly homogeneously throughout the study area (Figure 2) and therefore it can be assumed that taking into account the minor disproportionalities in the age-structure of the populations when weighing the temperature in order to obtain a spatial average would have only a minor impact on the final temperature time series.

\section{Conclusion}

A relationship between high temperatures and cardiovascular mortality was observed for cerebrovascular diseases, ischaemic and other heart diseases, with the highest risk associated with ischaemic heart diseases. The relationship is strongest on the actual day of the event and the relative risk remains significantly elevated for approximately one day following the event. The increase in risk is most evident on days with the highest temperatures. The highest relative risks are observed for the daily mean temperature time series, which suggests that consecutive high day- and night-time temperatures are the most hazardous.

The identification of this relationship in Cyprus raises concerns especially in light of the climate projections indicating a large increase in hot weather extremes in the region. The findings of this study will be used in a follow-up study with the goal of establishing and testing a function representing the past temperature- mortality relationship and future projections for the entire EMME region, under the hypothesis that such a function established for Cyprus will be more representative of the EMME region than the functions used for other parts of the world.

With its focus on Cyprus, a part of a geographical region that is under-represented in the existing literature on heat-related mortality, and its focus on specific categories of cardiovascular diseases, this study adds new knowledge to the existing literature. Moreover, the 
identification of susceptible populations to heat-related cardiovascular mortality can improve the choice and implementation of adaptation measures and therefore facilitate the prevention and control of heat-related harmful effects of climate change.

\section{Additional files}

Additional file 1: Weighting factors of the meteorological data [34].

Additional file 2: Table S1. QAIC and QBIC for different combinations of temperature $\mathrm{df}$ and lag $\mathrm{df}$. The model with the best fit is indicated in bold.

Additional file 3: Table S2. Results from the sensitivity analysis. Relative risk (RR) values corresponding to three different temperature percentiles are shown, as well as the accompanying $95 \% \mathrm{Cl}$.

Additional file 4: Table S3. Results from the sensitivity analysis. Relative risk (RR) values corresponding to three different temperature percentiles are shown, as well as the accompanying $95 \% \mathrm{Cl}$.

\section{Abbreviations}

EMME: East Mediterranean and Middle East; ${ }^{\circ} \mathrm{C}$ : Degrees celsius; ICD10: $10^{\text {th }}$ revision of the International Classification of Diseases; $T_{\text {max }}$ : Maximum temperature; $T_{\text {mean: }}$ : Mean temperature; $T_{\text {min }}$ : Minimum temperature DLNM: Distributed lag non-linear model; Cl: Confidence interval.

\section{Competing interests}

The authors declare that they have no competing interests.

\section{Authors' contributions}

Developed and coordinated the study: MJL, JL. Analyzed the data: MJL. Interpreted the data, results, and wrote the paper: MJL, CAC, JL. All authors read and approved the final version of this manuscript.

\section{Acknowledgements}

We acknowledge the Cyprus Meteorological Service and AGWATER project for their cooperation.

\section{Sources of funding}

The research leading to these results has received funding from the European Research Council under the European Union's Seventh Framework Programme (FP7/2007-2013) / ERC grant agreement $n^{\circ} 226144$ (C8 project).

\section{Author details \\ ${ }^{1}$ Energy, Environment and Water Research Center, The Cyprus Institute, Nicosia, Cyprus. ${ }^{2}$ Cyprus International Institute for Environmental and Public Health in association with Harvard School of Public Health, Cyprus University of Technology, Limassol, Cyprus. ${ }^{3}$ Department of Environmental Health, Harvard School of Public Health, Boston, MA, USA. ${ }^{4}$ Max Planck Institute for Chemistry, Mainz, Germany.}

\section{Received: 12 December 2014 Accepted: 21 April 2015}

Published online: 01 May 2015

\section{References}

1. Gabriel KMA, Endlicher WR. Urban and rural mortality rates during heat waves in Berlin and Brandenburg. Germany Environ Pollut. 2011:159(8-9):2044-50.

2. Gosling SN, Lowe JA, McGregor GR, Pelling M, Malamud BD. Associations between elevated atmospheric temperature and human mortality: A critical review of the literature. Clim Change. 2009;92(3-4):299-341.

3. McMichael AJ, Woodruff RE, Hales S. Climate change and human health: Present and future risks. Lancet. 2006:367(9513):859-69.

4. Sheridan SC, Kalkstein AJ, Kalkstein LS. Trends in heat-related mortality in the United States, 1975-2004. Nat Hazards. 2009:50(1):145-60.

5. IPCC. Summary for Policymakers. In: Managing the Risks of Extreme Events and Disasters to Advance Climate Change Adaptation (Field CB, Barros V, Stocker TF, Qin D, Dokken DJ, Ebi KL, et al. A Special Report of Working Groups I and II of the Intergovernmental Panel on Climate Change. 2012; Cambridge University Press, Cambridge, UK, and New York, NY, USA, pp. 1-19.
6. Lelieveld J, Hadjinicolaou P, Kostopoulou E, Chenoweth J, El Maayar M, Giannakopoulos C, et al. Climate change and impacts in the Eastern Mediterranean and the Middle East. Clim Change. 2012;114(3):667-87.

7. Lelieveld J, Hadjinicolaou P, Kostopoulou E, Giannakopoulos C, Pozzer A, Tanarhte $M$, et al. Model projected heat extremes and air pollution in the eastern Mediterranean and Middle East in the twenty-first century. Reg Environ Change. 2014;14(5):1937-49.

8. Oudin Åström D, Forsberg B, Edvinsson S, Rocklöv J. Acute fatal effects of short-lasting extreme temperatures in Stockholm, Sweden: evidence across a century of change. Epidemiology. 2013;24(6):820-9.

9. Coates L, Haynes K, O'Brien J, McAneney J, Dimer de Oliveira F. Exploring 167 years of vulnerability: an examination of extreme heat events in Australia 1844-2010. Environ Sci Pol. 2014;42:33-44.

10. Petkova EP, Gasparrini A, Kinney PL. Heat and mortality in New York City since the beginning of the 20th century. Epidemiology. 2014;25(4):554-60.

11. Schifano $P$, Leone $M$, De Sario M, de'Donato F, Bargagli AM, D'Ippoliti D, et al. Changes in the effects of heat on mortality among the elderly from 1998-2010: results from a multicenter time series study in Italy. Environ Health. 2012;11(1):58

12. Zachariadis T, Hadjinicolaou P. The effect of climate change on electricity needs - a case study from Mediterranean Europe. Energy. 2014;76:899-910.

13. Oudin Åström D, Bertil F, Joacim R. Heat wave impact on morbidity and mortality in the elderly population: a review of recent studies. Maturitas. 2011;69(2):99-105

14. Basu R, Samet JM. Relation between elevated ambient temperature and mortality: a review of the epidemiologic evidence. Epidemiol Rev. 2002;24(2):190-202.

15. Bouchama A, Dehbi M, Mohamed G, Matthies F, Shoukri M, Menne B. Prognostic factors in heat wave-related deaths: a meta-analysis. Arch Intern Med. 2007:167(20):2170-6.

16. Fischer $\mathrm{EM}$, Schär $\mathrm{C}$. Consistent geographical patterns of changes in high-impact European heatwaves. Nat Geosci. 2010;3(6):398-403.

17. Hajat S, O'Connor M, Kosatsky T. Health effects of hot weather: from awareness of risk factors to effective health protection. Lancet. 2010;375(9717):856-63

18. El-Zein A, Tewtel-Salem M, Nehme G. A time-series analysis of mortality and air temperature in Greater Beirut. Sci Total Environ. 2004;330(1-3):71-80.

19. Nastos $M$. The effect of air temperature and human thermal indices on mortality in Athens, Greece. Theor Appl Climatol. 2012;108(3-4):591-9.

20. McMichael AJ, Wilkinson P, Kovats RS, Pattenden S, Hajat S, Armstrong B, et al. International study of temperature, heat and urban mortality: The 'ISOTHURM' project. Int J Epidemiol. 2008;37(5):1121-31.

21. CyStat. Census of Population 2011. Cyprus Statistical Service. http:// www.mof.gov.cy/mof/cystat/statistics.nsf/populationcondition_22main_en/ populationcondition_22main_en?OpenForm\&sub=2\&sel=2. Accessed: 14 February 2015

22. WHO. International Statistical Classification of Diseases and Related Health Problems. World Health Organization Library Cataloguing-in-Publication Data. 2010; $10^{\text {th }}$ revision, edition 2010

23. $\mathrm{MoH}$ (Ministry of Health). Health Monitoring Unit. http://www.moh.gov.cy. Database publicly not available. Received: 22 February 2013.

24. Cui J, Sinoway LI. Cardiovascular responses to heat stress in chronic heart failure. Curr Heart Fail Rep. 2014;11:139-45.

25. Crandall CG, Gonzalez-Alonso J. Cardiovascular function in the heat-stressed human. Acta Physiol. 2010;199(4):407-23.

26. MoA (Ministry of Agriculture). Department of Meteorology. http:// www.moa.gov.cy/moa/ms/ms.nsf/DMLcyclimate en/ DMLcyclimate_en?OpenDocument. Accessed: 15 May 2014

27. Guo Y, Barnett AG, Pan X, Yu W, Tong S. The impact of temperature on mortality in Tianjin, China: A case-crossover design with a distributed lag nonlinear model. Environ Health Perspect. 2011;119(12):1719-25.

28. Gasparrini A, Armstrong B, Kenward MG. Distributed lag non-linear models. Stat Med. 2010;29(21):2224-34.

29. Levy D, Lumley T, Sheppard L, Kaufman J, Checkoway H. Referent selection in case-crossover analyses of acute health effects of air pollution. Epidemiology. 2001:12(2):186-92.

30. Gasparrini A. Distributed lag linear and non-linear models in R: The package dlnm. J Stat Softw. 2011:43(8):2-20.

31. Braga ALF, Zanobetti A, Schwartz J. The effect of weather on respiratory and cardiovascular deaths in 12 U.S. cities. Environ Health Perspect. 2002;110(9):859-63. 
32. Grize L, Huss $A$, Thommen $\mathrm{O}$, Schindler $\mathrm{C}$, Braun-Fahrländer $\mathrm{C}$. Heat wave 2003 and mortality in Switzerland. Swiss Med Wkly. 2005;135(13-14):200-5.

33. Havenith G. Temperature regulation, heat balance and climatic stress. Extreme weather Events and Public Health Responses. 2005. p. 69-80.

34. Zoumides C, Bruggeman A, Zachariadis T, Pashiardis S. Quantifying the poorly known role of groundwater in agriculture: the case of Cyprus. Water Resour Manag. 2013;27(7):2501-14.

Submit your next manuscript to BioMed Central and take full advantage of:

- Convenient online submission

- Thorough peer review

- No space constraints or color figure charges

- Immediate publication on acceptance

- Inclusion in PubMed, CAS, Scopus and Google Scholar

- Research which is freely available for redistribution 